\title{
Vivências de alunos de enfermagem em estágio hospitalar: subsídios para refletir sobre a humanização em saúde
}

\author{
NURSING STUDENTS' EXPERIENCES IN HOSPITAL TRAINING: \\ SUBSIDIES FOR A REFLECTION ON HUMANIZATION OF HEALTH
}

VIVENCIAS DE ALUMNOS DE ENFERMERÍA EN LA PRÁCTICA HOSPITALARIA:
SUBSIDIOS PARA REFLEXIONAR SOBRE LA HUMANIZACIÓN EN SALUD

Juliana Cristina Casate ${ }^{1}$, Adriana Katia Corrêa ${ }^{2}$

\section{RESUMO}

A proposta deste estudo qualitativo é compreender as vivências de alunos do Curso de Graduação em Enfermagem nas situações de estágio no cotidiano hospitalar, refletindo sobre o processo de formação, com ênfase na dimensão humana. Essa compreensão pode oferecer subsídios para a reflexão sobre a humanização da prática em saúde/enfermagem. Foram realizadas 13 entrevistas individuais com discentes que finalizavam o $6^{\circ}$ e iniciavam o $7^{\circ}$ semestre, nos meses de novembro/dezembro de 2003 e fevereiro/ março de 2004. Da análise das entrevistas emergiram temas significativos: deparar-se com o sofrimento do outro é experiência "humanizante"; dicotomia saber técnico/saber humano; valorização da dimensão humana: aprendizagem teórica; a equipe de saúde como modelo de (des) aprender; as experiências de estágio despertam sentimentos nos alunos; relação aluno-professor: limites e facilidades. É necessário repensar o processo de formação, investindo em ações articuladas que favoreçam transformações nos serviços e nas escolas, envolvendo professores, alunos e trabalhadores.

\section{DESCRITORES}

Educação em enfermagem. Estudantes de enfermagem. Humanismo.

Pesquisa qualitativa.

\begin{abstract}
This qualitative study aims at understanding undergraduate Nursing students' experiences in daily hospital training situations, reflecting on the formation process and highlighting the human dimension. Understanding this may give subsidies for a reflection on the humanization of health/ nursing practice. Thirteen students who were finishing the $6^{\text {th }}$ and beginning the $7^{\text {th }}$ semester in November/December 2003 and February/March 2004 were interviewed individually. The analysis of these interviews revealed the following important themes: being faced with other peoples' suffering is a "humanizing" experience; dichotomy technical knowledge/human knowledge; value of the human dimension: theoretical learning; the health team as a model of (un) learning; training experiences arouse feelings in the students; student-teacher relation: limits and facilities. There is a need to rethink the formation process, investing in coordinated actions that favor transformations in service and in schools involving teachers, students and workers.
\end{abstract}

\section{KEY WORDS}

Education, nursing.

Students, nursing.

Humanism.

Qualitative research.

\section{RESUMEN}

La propuesta de este estudio cualitativo fue comprender las vivencias de los alumnos del Pregrado en Enfermería en situaciones de práctica en el cotidiano hospitalario, reflexionando sobre el proceso de formación, con énfasis en la dimensión humana. Esa comprensión puede ofrecer elementos para la reflexión sobre la humanización de la práctica en salud/enfermería. Fueron realizadas 13 entrevistas individuales con discentes que finalizaban el $6^{\circ}$ e iniciaban el $7^{\circ}$ semestre, en los meses de noviembre/diciem-bre del 2003 y febrero/marzo del 2004. Del análisis de las entrevistas emergieron temas significativos: depararse con el sufrimiento del otro es una experiencia "humanizante"; dicotomía saber técnico/saber humano; valorización de la dimensión humana: aprendizaje teórico; el equipo de salud como modelo de (des) aprender; las experiencias de práctica despiertan sentimientos en los alumnos; relación alumnoprofesor: límites y facilidades. Es necesario repensar en el proceso de formación, invirtiendo en acciones articuladas que favorezcan transformaciones en los servicios y en las escuelas, involucrando a profesores, alumnos y trabajadores.

\section{DESCRIPTORES}

Educación en enfermería.

Estudiantes de enfermería.

Humanismo.

Investigación cualitativa.
Graduanda em Enfermagem de Ribeirão Preto da Universidade de São Paulo (EERP-USP), bolsista PiBIC/CNPq. jcasate@yahoo.com.br 2 Enfermeira. Professora Doutora da EERP-USP. (Orientadora) 


\section{INTRODUÇÃO}

Temos nos questionado sobre até que ponto a formação dos trabalhadores em saúde, especificamente em enfermagem, vem dando conta de propiciar o desenvolvimento de competências que favoreçam uma atuação que contemple o homem em sua integralidade, complexidade e singularidade, valorização essa fundamental para a constituição de um fazer humano em saúde.

Tendo em vista nosso envolvimento com o campo hospitalar, a prática de estágio nesse local pode ser valiosa, ao favorecer que $o$ aluno vivencie situações cotidianas que $o$ coloque frente a frente com a realidade concreta. Nesse sentido, questionamos: serão os campos de estágio hospitalares utilizados como espaço para construção de competência humana? Como vêm se mostrando ao discente as experiências vividas nesse cenário de aprendizagem?

Cabe ressaltar que, atualmente, no contexto das Diretrizes Curriculares Nacionais dos Cursos de Graduação em Enfermagem $^{(1)}$, é claramente apontado como objetivo garantir a capacitação dos profissionais de saúde em relação à autonomia e discernimento para assegurar a integralidade da atenção e a humanização do atendimento de indivíduos, famílias e comunidade. Nesse sentido, dentre outros aspectos, são valorizadas as dimensões éticas e humanísticas da formação, orientadas à cidadania e à solidariedade. Construir compromissos e valores humanos no contexto da formação é essencial para a construção de uma prática humana em saúde.

Assim, a proposta deste estudo é compreender as vivências de alunos do Curso de Graduação em Enfermagem nas situações de estágio no cotidiano hospitalar, refletindo sobre o processo de formação, com ênfase em sua dimensão humana. Essa compreensão pode oferecer subsídios para a reflexão sobre a humanização da prática em saúde/enfermagem.

\section{CAMINHO METODOLÓGICO}

Neste estudo, foram utilizadas algumas idéias do referencial fenomenológico de investigação qualitativa, considerando a natureza do objeto de pesquisa.

As pesquisas de abordagem fenomenológica na enfermagem devem estar centradas em questões que têm o sujeito como pessoa que vivencia o mundo de modo próprio(2).

Em se tratando de um estudo de iniciação científica, a aproximação à abordagem fenomenológica, limitou-se à valorização do contexto vivencial, à compreensão inicial da dimensãofenômeno no enfoque da temática e, principalmente, ao despertar para a possibilidade de desenvolvimento da atitude fenomenológica de acesso aos sujeitos e coleta de dados.
Após aprovação do projeto no Comitê de Ética em Pesquisa da Escola de Enfermagem de Ribeirão Preto da Universidade de São Paulo, foram realizadas 13 entrevistas individuais com discentes que estavam finalizando o $6^{\circ} \mathrm{e}$ iniciando $07^{\circ}$ semestre da graduação dessa escola, tendo em vista que já tinham se aproximado da prática hospitalar em algumas disciplinas cursadas e, muitas vezes, em situações formais e informais de ensino, já revelavam alguns questionamentos sobre as suas experiências vividas em estágios no hospital.

Inicialmente, todos os alunos deste semestre foram informados sobre a realização desta pesquisa, sendo aguardada a manifestação de seu interesse em participar nesta investigação. Após essa, as entrevistas foram agendadas previamente, fora do horário das atividades curriculares, sendo realizadas nas próprias dependências da escola, nos meses de novembro/dezembro de 2003 e fevereiro/março de 2004, seguindo os preceitos éticos concernentes à pesquisa com seres humanos ${ }^{(3)}$.

Tendo sido autorizado pelo discente, foi utilizado o gravador em todas as entrevistas. Tal entrevista foi aberta e dirigida pela questão norteadora: Conte-me como tem sido para você as experiências de estágio em hospital, ao longo do seu processo de formação.

Quando os dados coletados mostraram-se suficientes, tendo em vista a interrogação do estudo, o que está relacionado à convergência das falas, como também às experiências divergentes relatadas pelos sujeitos, possibilitando que o fenômeno se mostre em algumas facetas, as entrevistas foram finalizadas.

Em seguida, as entrevistas foram lidas, em sucessivas aproximações, sendo buscadas, inicialmente, em cada uma, unidades significativas, considerando a proposta do estudo. Posteriormente, as entrevistas foram articuladas umas às outras, emergindo temas comuns, apresentados a seguir, a partir dos quais foram sendo configuradas as experiências de estágio hospitalar pelo discente de enfermagem, sendo analisada a sua formação humana.

\section{ANÁLISE DAS ENTREVISTAS}

\section{Deparar-se com o sofrimento do outro é experiência "humanizante"}

Os discentes referem que, em alguns estágios, deparamse com o sofrimento da pessoa doente e essa aproximação à fragilidade do outro desperta neles a sua própria dimensão humana, o que os sensibilizam para o cuidar. Porém, ao mesmo tempo, tal aproximação torna-os vulneráveis ao sofrimento. 
Essa fragilidade revela-se por meio de situações comumente encontradas no hospital e que mostram o quanto a pessoa internada está sujeita a experiências dolorosas que cerceiam sua liberdade, invadem sua privacidade, impedem realizar atos comuns do dia a dia, como falar e caminhar, que levam à perda da consciência de si mesmo, deixando a pessoa humana à mercê da ação do profissional de saúde.

Alguns alunos, nesse contexto, referem que sofrem ao cuidarem dos pacientes, sentindo tristeza e preocupação com a sua condição. Algumas vezes, esses sentimentos extrapolam o cenário hospitalar, acompanhando-os em seu cotidiano. Eles têm lembranças de situações vividas no estágio, chegam a sonhar com alguns pacientes e relacionam algumas dessas situações com experiências vividas no contexto da família, como, por exemplo, reconhecendo, no familiar doente, características como idade, patologia, modo de lidar com a doença, que marcaram pessoas hospitalizadas com as quais tinham entrado em contato.

Além disso, a falta de preparo para o cuidar e para o enfrentamento de experiências marcadas pelo sofrimento humano é relatada por alguns alunos como dificuldades a serem consideradas.

Algumas falas expressam essas idéias:

(...) eu passo as coisas que o paciente tá passando como se poderia ser comigo (...) [E5 - E5].

(...) sabe quando você fica imaginando, nossa eu vi uns velhinhos lá, pode, podia ser meu avô sabe assim, que tava lá... (...) [E5].

(...) sabe quando você vai pra casa e fica pensando na pessoa, na família, como é que é, como é que não é a vida dessa pessoa... fora daqui desse hospital (...) [E11].

(...) eu chegava do estágio às vezes, eu chegava, ligava pra minha mãe chorando... desesperada assim... me sentindo a pior pessoa do mundo por não poder... assim saber que eu tava fazendo alguma coisa pra ajudar, porque no estágio você faz... mas ao mesmo tempo... me sentindo mal assim... porque às vezes a gente reclama, que nem eu falei, de tanta coisa e é tudo tão perfeito na nossa vida assim, lógico todo mundo tem... seus problemas aí, mas... né, perto de uma pessoa que tá lá, a gente não tem nada de problema.... (...) [E11].

(...) cuidar de um paciente, muita responsabilidade, a gente não cuida nem... nem da gente direito ainda, vai cuidar de... outro ser humano (...) [E7].

Essa aproximação ao sofrimento do outro coloca o aluno diante de seus próprios conflitos, frustrações, de sua própria saúde ou doença, tornando-o vulnerável ao sofrimento. E esse sofrimento se dá, muitas vezes, pela identificação dos alunos com os pacientes que sofrem ${ }^{(4)}$.

Compreendemos que o reconhecimento da condição humana é possível quando o aluno consegue perceber o paciente em seu contexto de vida subjetivo e social, o que nem sempre é valorizado no trabalho hospitalar em comparação a outros contextos de estágio.

Assim, é explicitado por um discente que a prática em saúde pública foi a mais significativa no sentido de aproximá-lo da realidade vivida pelas pessoas, entrando em contato com a pobreza, as condições difíceis de vida, diferentes de sua própria realidade, o que também é fonte de sofrimento:

Como já comentado, no contexto hospitalar, muitas vezes, é pouco considerada a dimensão subjetiva e social da pessoa hospitalizada, o que é percebido por alguns alunos que comentam sobre a própria formação tecnicista, marcada pela dicotomia saber técnico/saber humano.

\section{Dicotomia saber técnico/saber humano}

A dicotomia saber técnico/humano é percebida em alguns relatos dos alunos quando mostram que as preocupações iniciais, nos primeiros estágios, estavam dirigidas estritamente para a execução da técnica correta, seja para aprender ou mostrar para o professor, e também para a quantidade de técnicas realizadas, buscando garantir que seja executado o maior número possível de procedimentos.

A ênfase da ação do aluno se volta para o fazer técnico desarticulado da compreensão do doente em sua integralidade.

(...) e acho que como no começo também a gente tá muito preocupado no aprender, nas técnicas, nessas coisas, a gente até acaba esquecendo um pouco o paciente lá (...) [E6].

(...) eu acho que simplesmente você faz só as técnicas e olhe lá... vamos supor, você vai puncionar a veia de um paciente, você... eu creio que você nem olha pro paciente, você esqueceu que ali tem um paciente, só tem uma veia e uma agulha que você vai puncionar e mais nada, então, não consegue nem falar pra ele 'é a primeira picada', não, você nem lembra... (...) [E12].

(...) a gente não tinha muita noção do... dos direitos, e nem... e nem de como tratar mesmo a pessoa assim... de uma maneira boa, sem... sem deixar de fazer as técnicas, ou era a técnica ou você tratava o paciente bem, os dois não dava muito bem, mas depois eu acho que foi melhorando assim (...) [E6].

Cabe considerar que conforme explicitado na entrevista 6, para o aluno, o aprender se reduz ao aprendizado técnico.

Como mostrado em outro estudo ${ }^{(5)}$, o aprendizado técnico é fonte de ansiedade para os alunos: $81,8 \%$ de discentes entrevistados falaram sobre sua ansiedade quanto ao aprendizado técnico, o que está relacionado com o medo de errar e prejudicar o paciente. 
$\mathrm{Na}$ realização da técnica, o aluno se comunica pouco com o paciente, restringindo sua fala ao aviso do procedimento a ser realizado ${ }^{(6)}$.

A separação saber técnico/humano também é percebida pelos próprios alunos, quando referem que no início da prática hospitalar não tinham muita preocupação com as dimensões emocional e social do paciente, envolvendo os temores, dificuldades, sentimentos, crenças, condições de vida.

Apesar disso, os alunos revelam, em suas falas, que têm, teoricamente, noção da necessidade de o paciente ser visto em sua integralidade, "totalidade", desde de seu primeiro contato com o profissional que dele cuida. Todavia, referem ainda que é muito difícil concretizar essas noções teóricas nas ações de cuidado, prevalecendo a dicotomia mencionada.

(...) o que a nossa faculdade mais valoriza seria justamente o que a gente aprende em todos os anos (...) ter uma relação com o paciente assim... não só o lado biológico, mas você ver o lado humano do paciente, você tá... você valorizar as emoções, você respeitar, ver como um cidadão, e a gente acaba não fazendo isso no estágio, pelo menos eu, porque a gente tá tão preocupado em fazer a técnica (...) [E1].

Desse modo, cabe considerar que os conceitos tão enfatizados ao longo da formação acerca do homem em sua totalidade, em seus aspectos biopsicossociais, como um todo ficam no plano teórico, quase que restritos às disciplinas da área de humanas, desarticulados das demais disciplinas e do cuidar cotidiano. É sobre isso que passamos a discorrer a seguir.

\section{Valorização da dimensão humana: aprendizagem teórica}

A formação em enfermagem tem valorizado a inclusão de conteúdos que abordam o homem em sua dimensão humana, envolvendo questões subjetivas e sociais, na tentativa de ampliar a perspectiva biológica, clínica e técnica do cuidar em saúde.

Porém, como já comentado, o modo como esses conteúdos são ministrados faz com que sejam compreendidos de forma abstrata pelos alunos, já que eles não são articulados com os conteúdos clínicos, vistos posteriormente. É como se fosse esperado que os alunos sozinhos fizessem essa articulação, no decorrer da prática clínica hospitalar, o que é pouco provável.

De qualquer modo, em algumas entrevistas, percebemos que os discentes se referem a concepções sobre a totalidade da pessoa humana e acerca da importância de humanizar a assistência, reproduzindo o discurso da formação, e ao mesmo tempo, questionando-as, o que pode ser visualizado nas falas a seguir:
(...) depois que a gente foi... tendo mais aulas de... de Bioética, eu acho que a gente tinha que ter tido antes, porque no $3^{\circ}$ ano a gente já passou por dois estágios... então, a gente... eu acho que a gente devia ter tido antes pra ter uma noção do que... do que o paciente pode escoIher, o que ele não pode, o que é direito, o que é dever, essas coisas... (...) [E6].

É enxergar a pessoa assim além da doença dela, vê que... ela tá ali no hospital, mas que ela tem a família dela, na casa dela, ela tem os filhos, ela tem... é... o bairro onde ela mora, ela tem os vizinhos, ela tem um... tem um... contexto dela de vida, que ela não... não é só aquilo que ela tá... que tá ali na nossa frente sabe?, a doença dela... e aquele ser precisando de um soro, de um medicamento... que ela precisa de muito mais que isso pra conseguir sair dali bem... é preciso que a gente enxergue que ela tem isso tudo a mais [E9].

(...) eu acho que é isso que a gente tem que ter pra conseguir fazer mesmo esse trabalho, esse blá blá blá que a enfermagem joga, que tem que ser o paciente como um ser... um ser... ver o paciente como um ser todo, tal, não ficar só visando no cuidado (...) [E3].

(...) o que eu acho muito errado, é a gente chegar aqui na faculdade, elas jogarem, jogarem, jogarem pra gente que esse negócio de... eu já falei isso mil vezes né, mas ser holístico tal, a gente tem isso na teoria, então a gente procura... a gente busca isso (...) [E3].

Estudos já mostram ${ }^{(4)}$ que os conhecimentos sobre a natureza e o desenvolvimento de atitudes de valorização do homem são fundamentais para a humanização, sendo prioritário que os currículos incluam conteúdos relativos aos aspectos psicológicos, sociológicos e antropológicos na área da saúde. As matérias humanísticas podem contribuir na busca por novas abordagens em saúde.

Todavia, não basta garantir que sejam ministrados conteúdos teóricos de forma separada, ficando difícil para o discente estabelecer relação com a prática, já que, conforme mencionado nas falas dos alunos, as disciplinas humanísticas são ministradas nos primeiros anos e os conteúdos clínicos a partir do terceiro ano, ficando uma distância razoável entre eles.

Cabe considerar que, apesar da fragilidade dos conhecimentos relativos à dimensão humana, é por meio deles que os alunos observam, nos estágios hospitalares, a atuação da equipe de saúde/enfermagem no cuidado ao doente.

Nessa observação, eles (des) aprendem o que seja uma postura humana e ética.

\section{A equipe de saúde como modelo de (des) aprender}

Conforme as falas de alguns alunos, eles sentem que, durante o estágio hospitalar, pouco se inserem na equipe de saúde/enfermagem, porém, essa equipe é seu foco de aten- 
ção: eles observam suas ações, relatando atitudes inadequadas que ferem princípios éticos e humanos, demonstrando que alguns profissionais estão preocupados somente em fazer a técnica, apresentando, muitas vezes, descaso em relação ao paciente:

(...) o pré-cirúrgico assim é... é um momento delicado né, as pessoas ficam com, choram... e... e aí às vezes você vê a pessoa que trabalha lá, a enfermeira, técnico, falando 'ai, uma cirurgia tão pequena... ai não é nada, não precisa chorar desse jeito, credo' sabe?, mas não é, às vezes a pessoa até sabe que é pequena, tudo, mas é... é o medo né, é insegurança de você não saber o que está acontecendo (...) [E6].

(...) uma coisa que eu acho muito difícil, é você olhar pro paciente e tentar vê no... no contexto que não seja só no biológico... porque... tem pessoas que ah não, que acham que... que nem essa... essa paciente do câncer... ela não queria de jeito nenhum sair do hospital... não queria ter alta, ela tinha medo de ir pra casa dela, e tinha enfermeira ali que falava que era frescura dela (...) [E8].

(...) a maioria dos profissionais demonstra um pouco de descaso no tratamento com os pacientes (...) [E1].

(...) quando você chega como aluno, você aprende, por exemplo, você aprende uma coisa... que é ser holístico tal, tudo bonitinho... tem que ser legal, tem que ser generoso, tem que fazer as coisas certinhas... anotação... tudo perfeitinho, a gente vê tudo de um jeito, a gente chega lá... a gente procura fazer tudo, a gente é cobrado pra fazer do jeito que a gente aprende na sala de aula né, a gente dá tudo da gente, só que aí nesses quatro anos, a gente vê que não funciona assim com as outras pessoas que já estão dentro da instituição (...) [E3].

(...) o auxiliar vai lá, dá o banho... mas num... sabe? Não quer fazer aquilo que ele tá fazendo (...) o paciente precisa de ajuda pra comer... ele não vai dar comida (...) não vai tentar aliviar mesmo o mínimo, mesmo de que... de que seja um curativo, faz de qualquer jeito sabe?, não faz com cuidado, não procura... realmente saber as necessidades daquela pessoa (...) [E3].

Cabe considerar que apenas uma fala ressalta uma atitude do trabalhador considerada adequada pelo discente:

(...) você observa muito, pelo menos eu observei muito isso, entre os bons profissionais aqueles que não ficam brincando durante a cirurgia, que tem uma posição... meIhor do que outros (...) [E7].

Críticas e questionamentos são apontados pelos alunos em relação à atuação dos trabalhadores, sendo apontados o predomínio de um fazer mecânico e tarefeiro ${ }^{(7)}$ e a frieza/ descrédito da enfermeira no que se refere ao sofrimento dos pacientes, o que desperta no aluno o medo de também se tornar indiferente em sua futura prática profissional ${ }^{(8)}$.

Do que foi exposto até então, fica nítido que as experiências dos alunos nos campos hospitalares despertam senti- mentos diversos, mostrando que a aprendizagem não está restrita a conhecimentos de ordem técnica e clínica, implicando também lidar com esses sentimentos.

\section{As experiências de estágio despertam sentimentos nos alunos}

As entrevistas apontam sentimentos de ansiedade, medo, frustração, insegurança, tristeza e impotência, relacionados às situações difíceis enfrentadas pelo aluno junto aos pacientes, equipe de saúde, professores e demais colegas, bem como gratificação e motivação quando os discentes sentem-se reconhecidos pelo paciente/família ou pelo docente e ao sentirem que foram úteis ao doente hospitalizado:

(...) a primeira vez que eu fui pro hospital, eu perguntei pro paciente se ele não ia comer e ele tava com sonda, daí eu já fiquei frustrada, porque ele que me falou que ele tava com sonda e que era pra comer, não sabia pra que era a sonda, se era pra ele respirar, o que era, não sabia, nunca tinha visto uma sonda na minha vida, daí eu já fiquei frustrada (...) [E2].

(...) às vezes a gente sente-se impotente ainda porque como é aluno, às vezes sabe que muita coisa não pode fazer ou que não faz direito, depois que acaba o estágio, você fala 'nossa, podia ter feito daquele jeito, de tal jeito' (...) [E2].

(...) eu comecei bastante ansiosa... ansiosa e com medo do... do contato com o paciente, que ia ser o contato assim mais... é... o...não sei, ia ser estranho pra mim assim, ter que conversar com o paciente né, saber dele tudo (...) [E8].

Dos estágios todos assim... no começo... eu sinto muito medo... insegurança... e é... difícil assim, você passar por cima disso... medo de fazer a coisa errada (...) [E8].

(...) eu gostei bastante, foi muito bom, muito bom, muito bom, ainda mais que eu tive o reconhecimento de uma... mãe de um paciente que mandou flores pra gente sabe?, foi muito legal assim, até então eu não sabia... eu não sabia da minha importância... que... o que eu signifiquei pro cuidado... dele (...) [E3].

O cuidar do outro mobiliza sentimentos e, assim, as experiências de ensino-aprendizagem envolvem a dimensão emocional do aluno, a qual nem sempre é considerada pelos docentes. Contudo, é necessário refletir sobre estratégias que minimizem os desconfortos no sentido de facilitar seu desenvolvimento integral ${ }^{(9)}$.

Cabe destacar que muitos desses sentimentos estão relacionados, na fala dos entrevistados, ao vínculo que o discente estabelece com o doente. Esse vínculo, tão enfocado como primordial para a humanização da assistência, pode tanto gerar sentimentos gratificantes como ser fonte de sofrimento para o aluno: 
(...) eu me apego muito aos pacientes assim, não de... mas ai, eu fico pensando muito neles assim, e depois ... tipo querer meio que proteger (...) [E5].

(...) eu me apeguei muito a... a essa paciente (...) altos papos a gente ficava conversando (...) [E5].

(...) eu lembro que um... paciente que eu me apeguei muito... (...) e quando ele foi embora, eu lembro que no dia seguinte, que eu sabia que ele não ia tá lá, eu não fui pro estágio com a mesma empolgação (...) [E11].

(...) foi um estágio que eu assim sofri bastante... eu achei assim, sofri no sentido de... porque eu fico, eu me apeguei [aos pacientes] muito entendeu?, então foi difícil nesse sentido.... (...) [E11].

Ao enfocarem a relação estabelecida com o doente, emergem falas que mostram sinais de uma visão caritativa, denotando sentimento de piedade. Por outro lado, há falas que evidenciam a necessidade de considerar a autonomia do paciente sobre seu cuidado, como fator importante para a humanização da assistência:

(...) tudo ela [paciente] me chamava 'tadinha'... só que aí, depois sabe quando você fica até com 'dózinho' assim da pessoa (...) [E5].

(...) e tinha uma senhora lá que 'tadinha' nossa ela... tava muito mal assim (...) [E5].

(...) só depois que a gente foi ter idéia de que a gente podia perguntar se o paciente queria ou não... esse negócio, ele tem autonomia pra decidir se ele quer ou não fazer aquele procedimento, e a gente nem falava nada, chegava lá... 'oh, vou passar essa sonda'... 'tá bom' né, não falava 'você quer, gostaria', 'quer tentar fazer xixi de novo?', não ia lá e fazia (...) [E6].

Essa compreensão da humanização em uma perspectiva caritativa em confronto à valorização da autonomia do paciente foi também enfocada em estudo bibliográfico voltado à análise dos conhecimentos construídos acerca da humanização em saúde/enfermagem ${ }^{(10)}$.

Um ponto significativo, verbalizado por poucos alunos, diz respeito ao enfrentamento da situação de morte vivida pelo discente como momento difícil e que desperta sentimentos intensos:

(...) o que eu vejo bastante no hospital, e que mais me chama a atenção assim, é às vezes... a morte assim, que o pessoal não sabe lidar muito bem, às vezes isso me choca um pouco (...) tinha um paciente terminal e que... não foi nada legal assim, foi que tipo... o paciente já era terminal e ninguém podia entrar no quarto, inclusive a gente, a professora nem punha a gente pra fazer estágio, e todo dia na passagem de plantão falava que tava com prognóstico fechado, então assim... não era um paciente, era um prognóstico fechado (...) [E2].
(...) eu nunca tinha passado por essa situação do óbito de um paciente... e nessa hora assim a gente, o hospital pareceu ser o lugar mais frio do mundo pra mim... eu fui levar o corpo do paciente... e... você andar assim com o paciente inteiro coberto, cabeça, tudo, que... o corredor era interminável, essa hora eu só via assim as paredes do hospital, aquela maca que eu tava empurrando e todo mundo, mas todo mundo mesmo, olhando pra mim, olhando pras meninas que tavam comigo levando o corpo e todo mundo parece que sabia, parece não, eles sabiam com certeza que aquilo era um corpo... e foi assim muito, muito, mas muito horrivel mesmo, foi acho que... a pior situação que eu passei em estágio por enquanto até agora assim que... é uma... um sentimento de impotência muito grande... parece que você ta ali assim... você não ajuda a pessoa em nada assim, você vê a... mulher, a esposa do paciente, ela chorava e você... o paciente tava lá assim, a gente só tirou ela da enfermaria mesmo... pra ela não vê o marido dela morrer assim, dá o último suspiro, nem sei se é o certo, porque... quem me garante que ele não queria que ela tivesse lá segurando a mão dele (...) [E4].

No contexto hospitalar, os pacientes se queixam que a equipe de enfermagem limita-se a prestar cuidados mínimos, o que revela um distanciamento da situação de terminalidade pelos membros dessa equipe ${ }^{(11)}$.

Compreendemos que o distanciamento da situação de terminalidade faz parte também da formação do profissional da saúde. Nesse sentido, as escolas mostram-se reticentes à implantação de um processo pedagógico dirigido a esse tema e, quando o faz, limita-se a um enfoque técnico centrado em condutas a serem realizadas frente a situações críticas ${ }^{(12)}$.

Muitos dos sentimentos vividos pelos alunos, como já comentado, envolvem a relação aluno-professor construída no processo ensino-aprendizagem no contexto do estágio hospitalar. Relação essa que pode tanto facilitar como limitar a aprendizagem.

\section{Relação aluno-professor: limites $e$ facilidades para a aprendizagem}

Algumas entrevistas enfatizam os diversos modos que o professor lida com o aluno no estágio hospitalar. Dessas, a maioria traz comentários, feitos pelos alunos, sobre a postura rígida do professor, a dificuldade de estabelecer uma relação empática, o sentimento de perceber o professor como ameaça:

(...) a professora era muito brava, a gente não podia perguntar nada e ela tava passando por um momento difícil, então assim... a gente sabe que tanto pra ela como pra gente, eu acho que... que o lado pessoal tava marcado assim... porque ela afetava a gente e a gente afetava ela também (...) [E2].

(...) é lindo o que elas colocam pra gente, só que nem elas como professoras... vêem a gente como um aluno... como um todo (...) [E3]. 
(...) foi um estágio assim que eu saía do hospital chorando... chorando, chorando, chorando, chorando no hospital, e... não conseguia, eu acho que ... pra dar certo um estágio, o professor tem que ter didática antes de tudo, pra ele querer ir pro campo de estágio, eu acho que... tem... ele tem que saber como lidar com os alunos, eu acho que essa professora... sob o meu ponto de vista não soube... então, cada vez eu fazia coisa pior, coisa pior, coisa pior e o meu erro ia ficando cada vez pior, quando eu via ela perto de mim, parece que tudo que eu tinha aprendido, eu esquecia tudo de uma vez assim... (...) [E4].

(...) acho que isso faltava nela [professora] passar segurança pra mim, mas passar uma segurança que eu pudesse confiar nela e não visse ela como uma pessoa que me ameaçava... que tava lá pra me fazer mal e não pra me ajudar [E4].

Por outro lado, em outras entrevistas, os discentes referem que se sentem acolhidos pelo professor, relatando experiências nas quais puderam expor seus sentimentos em relação a situações difíceis enfrentadas por eles, dialogando com o docente. No diálogo, o professor pode se fazer mais próximo do aluno, expondo também alguns de seus limites:

(...) adorei a professora e ela me ... ela me... falava coisa assim que eu tava indo bem, mas que tinha também pontos pra melhorar, e aquilo foi, foi muito bom... com os pacientes também foi bem melhor... a interação, porque perto dela eu... eu tinha menos medo de fazer as coisas, perto dessa professora... eu tinha menos medo... e ela me deu um notão, uma super nota (...) [E8].

(...) eu vi aquele sofrimento dele [paciente] na hora do curativo, eu saí da sala... chorando que nem uma louca, e eu falei 'puta, a docente A vai me matar, né', porque você chora na frente do paciente, você ta demonstrando, mas ela foi tão assim... ela entendeu tanto, ela falou que 'é assim mesmo, que às vezes ela também tem vontade de chorar, que ela também já sofreu muito, mas que a gente vai amadurecendo e tudo mais (...) [E11].

Os alunos também descrevem sua percepção sobre o que é valorizado pelo docente no campo de estágio, o que mostra, implicitamente, a direção na qual o discente deve encaminhar suas atividades, bem como a relação estabelecida entre professor e doente, vista pelo aluno como exemplo a seguir ou motivo de crítica.

Assim, alguns docentes, na perspectiva do aluno, valorizam sobremaneira o desempenho técnico, outros também dão ênfase ao aspecto psicológico do doente e, para alguns alunos, a visão do professor quanto à dimensão humana é também limitada:

Têm vários tipos de... eu não posso generalizar... tem professores que você percebe que... que estão lá junto com o paciente, que estão lá junto com você, que está... fazendo tudo, ta mostrando pra você como tem que ser, pra você ter calma, pra você conversar. Tem professor que já não, está ali mas também está preocupado se você está fazendo a coisa certa, está até meio que inseguro, e fala pra você conversar com o paciente, mas não pra você dialogar, mas pra você ta explicando a técnica que você vai fazer no paciente. Eu acho que... ficar explicando a técnica só não é você valorizar assim... o lado humano, é... você tem que fazer isso, mas você tem que fazer mais, não somente isso, e tem professor que mostra mais esse lado só [E1].

(...) quando eu fiz estágio na enfermaria (...) eu sentia... que a docente $\mathrm{B}$ deixava a gente muito à vontade nesse sentido, então, ela não pegava muito nessa parte de procedimentos, eu percebi que ela dava muita importância pra esse lado de... do emocional, do... do psicológico assim, por isso até que eu acho que eu gostei muito.... (...) [E11].

(...) porque a gente fica preocupado que a professora fica mais assim ... na parte prática, na parte técnica das coisas (...) [E11].

O modo como o professor se faz presente e orienta as atividades de estágio é muito importante para o processo ensinoaprendizagem: o aluno espera apoio e escuta por parte do docente, desejando ser visto em sua integralidade e observa suas condutas, tomando-as ou não como exemplos a seguir.

Outros estudos ${ }^{(5-6,8-9)}$ apontam também a necessidade do professor desenvolver sua competência humana para lidar de modo sensível e compreensivo com os alunos em experiências de estágios.

\section{CONSIDERAÇÕES FINAIS}

Nos estágios hospitalares, os discentes enfrentam, muitas vezes, situações complexas, envolvendo sofrimento humano e conflitos reveladores da nossa fragilidade e vulnerabilidade. Ao se depararem com o sofrimento da pessoa doente, neles é despertada a sua própria dimensão humana, sensibilizando-os para o cuidar. Porém, ao mesmo tempo, isso os torna vulneráveis ao sofrimento.

Essas situações realmente exigem do aluno uma atitude de escuta, envolvimento, senso crítico e acolhimento, para a qual ele não está, muitas vezes, preparado.

Esse despreparo relaciona-se tanto à formação como à organização da prática hospitalar, nas quais ainda é predominante a dicotomia fazer técnico-fazer humano, representando limitações para a perspectiva de humanização das práticas em saúde.

Nesse sentido, é fundamental que o aluno seja acolhido em suas limitações e conflitos, sendo acompanhado no sentido de promoção de sua maturidade pessoal e profissional, para a formação não estritamente técnica de sua profissão, contemplando também a formação de cidadão, pessoa humana, cujo fazer sempre tem implicações nas dimensões social e existencial. 
Isso implica repensar o processo de formação, com ênfase na articulação de conteúdos das ciências humanas e conteúdos clínicos, bem como na articulação teórico-prática que favoreça transformações compartilhadas dos serviços e da escola, envolvendo novas relações entre professores, alunos e trabalhadores.

\section{REFERÊNCIAS}

(1) Xavier IM, Fernandes JD, Ceribelli MIPF. Diretrizes curriculares: articulação do texto e contexto: breve comentário. Bol Inf Assoc Bras Enferm. 2002;44 (2):6-7.

(2) Lopes RLM, Rodrigues BMRD, Damasceno, MMC. Fenomenologia e a pesquisa em enfermagem. Rev Enferm UERJ. 1995;3(1):49-52.

(3) Conselho Nacional de Saúde. Comissão Nacional de Ética em Pesquisa. Resolução n. 196, de 10 de outubro de 1996. Normas regulamentadoras de pesquisa envolvendo seres humanos. Brasília: Ministério da Saúde; 1996.

(4) Martins MCFN. Humanização das relações assistenciais: a formação dos profissionais de saúde. São Paulo: Casa do Psicólogo; 2001.

(5) Carvalho MDB, Pelloso SM, Valsecchi EASS, Coimbra JAHC. Expectativas dos alunos de enfermagem frente ao primeiro estágio em hospital. Rev Esc Enferm USP. 1999;33(2):200-6.

(6) Ângelo M.Vivendo uma prova de fogo: as experiências iniciais da aluna de enfermagem [tese]. São Paulo: Instituto de Psicologia da USP; 1989.
Nesse contexto, dentre outros aspectos, é imprescindível que os docentes, como participantes significativos do processo ensino-aprendizagem, busquem formas de contribuir para a construção de uma formação humana e ética, valorizando a sua responsabilidade de educador. Isso envolve ações políticas e pedagógicas no contexto institucional.

(7) Corrêa AK. O preparo profissional do aluno de enfermagem para o cuidado do doente grave: enfocando o contexto da existência humana. Ribeirão Preto: [s.n.]; 2002.

(8) Nascimento ES, Rodrigues AB, Ladeia BEM, Madureira MDS. O cotidiano de alunos de enfermagem no aprendizado prático da profissão. Rev Enferm. 1996;2(5):37-52.

(9) Esperidião E. Holismo só na teoria: a trama dos sentimentos do acadêmico de enfermagem sobre sua formação [dissertação]. Ribeirão Preto: Escola de Enfermagem de Ribeirão Preto/USP; 2001.

(10) Casate JC, Corrêa AK. Humanização do atendimento em saúde: produção científica na literatura brasileira de enfermagem. Rev Lat Am Enferm. 2005; 13(1):105-11.

(11) Boemer MR. A morte e o morrer. Ribeirão Preto: Holos; 1998.

(12) Zorzo JCC. O processo de morte e morrer da criança e do adolescente: vivências dos profissionais de enfermagem [dissertação]. Ribeirão Preto: Escola de Enfermagem de Ribeirão Preto/USP; 2004. 